[CHRISTOPHER BREWARD]'

National Galleries of Scotland/University of Edinburgh

E-mail: chris.breward@ed.ac.uk

\title{
A alta-costura como auto/biografia queer
}


0 prólogo da autobiografia do grande costureiro Christian Dior, traduzida para o inglês por Antonia Fraser, em 1958, proporciona um insight revelador sobre a vida pessoal de um homem cujo nome, mais do que qualquer outro, tornou-se sinônimo da produção de uma influente forma de feminilidade luxuosa e elegante, que definiu o imaginário e a cultura da indústria da costura nos meados do século vinte. Apresentando o conceito "Os Dois Christian Dior", o grande designer se queixa que,

Críticos comumente descrevem autores de memórias como se estivessem "se apoiando no passado". Eu jamais gostei dessa expressão... ela implica que o passado [do autor] estaria morto e enterrado... Estou convencido de que minhas melhores memórias ainda estão por vir, e que mesmo meu passado está pouco atrás de mim. Afinal, Christian Dior tem apenas nove anos de idade - o que explica porque o mais interessante sobre ele, para mim, não é o que já aconteceu com ele... mas o que virá a acontecer (DIOR, 1958, p. 9).

A triste previsão de Dior se torna ainda mais dura devido ao nosso conhecimento de sua morte inesperada cerca de um ano após esta publicação. Ainda assim, a marca para a qual ele deu seu nome sobrevive e prospera até o presente. É a marca de Christian Dior o foco de seu livro. Apenas os cinco capitulos finais abordam a sua vida privada, sua casa e a experiência familiar. Assim, Dior escreve,

\footnotetext{
Vocês concluirão... Que havia dois Christian Diors: e eu estou falando agora do Christian Dior costureiro, da Maison Christian Dior, avenida Montaigne número 30, nascido em 1947. Foi para contar a verdade sobre este segundo Christian Dior, de nove anos de idade, que o primeiro Christian Dior decidiu escrever este livro. Ele já tem sido sujeito de discussões imprecisas o bastante e eu senti que era hora de contar ao mundo fatos verdadeiros sobre ele... Escondido em uma casa magnifica na avenida Montaigne, ele é uma aglomeração de pessoas, vestidos, meias-calças, perfumes, panfletos de publicidade, fotografias da imprensa e, vez ou outra, uma pequena revolução sem sangue cujas reverberações são sentidas por todo o mundo (DIOR, 1958, p. 10).
}

Tratando-se do primeiro Christian Dior, de carne e osso, o autor é bem mais reticente, projetando para si a caracterização reclusa que contrasta deliberadamente com a figura pública pomposa de seu homônimo. Nas palavras de Dior:

Eu ofereço um tipo muito diferente de imagem: nasci em Granville, na Normandia, em 21 de janeiro de 1905, filho de Alexandre Louis Maurice Dior, manufatureiro, e Madeleine Martin, sua esposa. Sou, então, metade parisiense, metade normando e 
continuo apegado à minha terra natal Normandia, mesmo que agora eu raramente a visite. Eu gosto de todas as simplicidades da vida, como pequenas festas de amigos de longa data. Eu detesto o barulho e agitação do mundo e as mudanças violentas e repentinas. Mesmo assim, suprimir completamente esse personagem em encolhimento teria sido para mim uma forma de traição; teria também privado minha história de seus toques pessoais (DIOR, 1958, p. 10).

Eu sou fascinado por essa apresentação dupla de si e o que ela pode nos dizer sobre o estado, a prática e o entendimento popular da costura no período pós-guerra, até porque Dior não foi a única figura no mundo da moda a colocar sua vida e opiniões no papel. Seguindo a tradição pré-guerra de Poiret, Lucile e Schiaparelli, vários designers e jornalistas produziram obras reveladoras e comumente picantes sobre suas vidas na moda durante os anos 1950. Apesar de normalmente descartadas pelos historiadores como veículos não confiáveis de autopromoção, do meu ponto de vista apresentam de maneira única os personagens da costura unidos às suas intimidades, que merecem um exame mais minucioso.

Seus livros podem, de fato, operar no nivel da fofoca e das obsessões fúteis com o supérfluo, podem deixar o leitor contemporâneo um tanto apático, mas uma leitura nas entrelinhas oferece dicas valiosas sobre um mundo secreto e estranho, cujos produtos glamorosos disfarçavam tensões complexas entre uma criatividade individual e impulsividade psicológica, e um rígido sistema de controle industrial e social, enquanto também delineavam a energia produtiva gerada por tais tensões. Para não dizer tão grossamente, as palavras carregadas dos homens que criaram uma moda espetacular para mulheres ricas nos frágeis anos 1940 e 1950 fornecem uma visão privilegiada das formas específicas de expressão pessoal e material que são reapropriadas pelos acadêmicos de hoje para os estudos queer (HALPERIN, 2012). Dior pontua isto muito bem ao recorrer à literatura romântica do século $\mathrm{XIX}$, declarando que:

Meu célebre conterrâneo, Gustave Flaubert, uma vez defendeu um dos personagens em seus romances... com as palavras sábias "Madame Bovary sou eu". E se aquele outro Christian Dior um dia me envolvesse em uma situação similar, eu, com certeza, o defenderia com meu último suspiro: "Eu sou ele". Pois, que eu goste ou não, minhas mais íntimas esperanças e sonhos são expressas através de suas criações (DIOR, 1958, p. 10).

Antes de considerar as memórias de quatro personalidades-chave nas indústrias francesa e britânica da costura pós-guerra, talvez valha a pena refletir sobre o valor da biografia popular e sua proeminência como forma literária na metade do século XX. Como argumenta a historiadora do gêne- 
ro Catherine N. Parke, as grandes revoluções intelectuais da era Moderna Darwinismo, Marxismo e Freudismo - contribuíram para o modelo seguido pelas escritas biográficas subsequentes, mas foi a psicologia freudiana a que exerceu o mais profundo efeito. Seu legado predominante, a

convicção de que há uma vida secreta acontecendo dentro de nós que está apenas parcialmente sob nosso controle, [focou] a investigação biográfica nos privados e inconscientes direcionamentos motivacionais, particularmente aqueles cunhados na infância, [que são] compreendidos para moldar a vida pública e consciente (PARKE, 1996, p. 25).

Para o subgênero da autobiografia esse conceito era especialmente poderoso, intensificando a responsabilidade retórica dos autores de "serem fiéis a eles e à imagem que desejam apresentar ao público", amplificando as declarações de um teórico literário de que a autobiografia é essencialmente um "discurso de ansiedade" (PARKE, 1996, p. 32). Durante os anos 1950 essa inquietação, esse medo de que irreconciliáveis naturezas públicas e privadas poderiam ser reveladas a qualquer momento era agudo - $\mathrm{e}_{\text {, }}$ não supreendentemente, geralmente girava em torno da problemática do sexo. A publicação dos dois Relatórios Kinsey sobre a sexualidade humana nos Estados Unidos e na Grã-Bretanha em 1948 e 1953; o Macarthismo; $3^{\text {IO }}$ ] a convenção do comitê de Wolfenden para rever as leis britânicas sobre crimes de homossexualidade e prostituição em 1957; e o julgamento do livro 0 amante de Lady Chatterley por obscenidade, em 1960, oferecem apenas quatro exemplos das maneiras como identidade, liberdade e hipocrisia sexual estavam cada vez mais entrando em foco no debate público (HORNSEY, 2010, p. 28-34). E, no mundo da moda, o tipo de sexo mais questionado era o que acontecia entre os homens; como demonstrado perfeitamente pela respeitada jornalista de moda Edna Woolman Chase lidando com o "problema», na linguagem da época - em sua autobiografia Always in Vogue, de 1954:

Como não sei nada de biologia, glândulas e genes, eu não posso falar como autoridade médica, mas como alguém que já lidou com essas pessoas através dos anos e entre eles encontrou amigos calorosos e companheiros divertidos, minha impressão é que alguns homens e mulheres nascem com algumas deficiências que é impossivel para eles corrigirem, enquanto outros, que poderiam ser maridos, esposas e pais perfeitamente normais, têm, através de um senso de valores pervertido e não de sexo, deliberadamente escolhido este estilo de vida para si mesmos... Entre as nações, os franceses parecem ser melhores em combinar habilidade artística com virilidade. Certamente, no mundo da moda, muitos dos homens cujos interesses e subsistência revolvem no que os franceses chamam "chiffons" - tecidos e 
babados e a elegância das roupas feitas sob medida - estão alegremente casados com esposas gordas e confortáveis das províncias, que os alimentam com uma admirável bourgeois cuisine francesa e dão a eles o tanto de filhos que um casal típico francês sente que pode dispor. Pelo menos, era assim que costumava ser... (CHASE, 1954, p. 326).

Minha intenção neste ensaio não é revelar as propensões sexuais secretas dos grandes homens da costura, nem oferecer insights pseudopsicológicos como faz Woolman Chase; mas, sim, considerar as maneiras como certas alegorias do desejo, da repressão, da insinuação, da revelação e do romance modulam as descrições de si mesmos e de seus trabalhos, ao ponto de que a ansiedade contemporânea sobre gênero e identidade sexual inevitavelmente vem dar novas cores à atmosfera obsoleta das casas de costura dos anos 1950 e o rebuscamento artificial de seus produtos, contribuindo até mesmo para o estilo de seus designs e promoções. Em outras palavras, meu argumento é de que nós não podemos entender completamente a cultura da costura criativa no período sem considerar as dissonâncias sexualizadas que definiram seus conteúdos e representações - e obras biográficas dessa natureza oferecem um ponto de partida fascinante para isso.

Partindo do início e com a visão freudiana, é surpreendente como muitos dos costureiros compartilham memórias de uma infância comum, na qual o pequeno menino sensivel herda as habilidades práticas ou visionárias de uma tia ou avó costureira e segue uma carreira escolar solitária e perseguida enquanto desenha vestidos imaginários e retratos de estrelas de filmes em seus livros de exercícios. Pierre Balmain, por exemplo, sem timidez em proclamar sua genialidade, relata em sua biografia de 1964, My Years and Seasons,

Eu não lembro de uma época em que eu não me interessasse por desenhos de vestidos e pela intrigante relação dos materiais com a forma feminina... sempre que meu dever de casa estava feito e eu tinha um momento livre eu corria para ver minhas tias na Galeries Parisiennes (a loja de departamento local)... As duas ficavam levemente incomodadas sobre o que elas, provocantemente, chamavam de meu interesse feminino em vestidos, mas era tão genuíno que elas não podiam senão ficar impressionadas. Diziam-me que até mesmo com aquela idade eu tinha um gosto muito certeiro e, para a diversão dos clientes e assistentes, não hesitava em mostrá-lo (BALMAIN, 1964, p. 14).

Já o costureiro britânico Norman Hartnell, cujo Silver and Gold, de 1955, conta certamente como uma das mais estranhas e engraçadas autobiografias já escritas, afirma que este 
Interesse por moda começou com uma caixa de giz de cera. Como eu era uma criança doente, forçada a ficar na cama por longos períodos, eu costumava me sentar apoiado nos travesseiros, com um livro de colorir nos meus joelhos, tecendo desenhos brutos, mas fantásticos... Todos os meus livros escolares de matemática, geometria e álgebra estavam cobertos com rabiscos de vestidos e representações das atrizes principais da época... Eu tinha comprado e estudado tantas fotos de cartões postais que poderia desenhá-las ou seus vestidos de memória... então estava lá a senhorita Doris Keane rodopiando pelos sinais de álgebra em crinolinas de tule rosa bordadas com borboletas azuis, ou um vestido volumoso de veludo verde com rendas de Bruxelas (HARTNELL, 1955, p. 15).

Em contraste, o contemporâneo de Hartnell, Hardy Amies, oferece um relato mais resumido e direto, mas nem por isso menos revelador, de suas influências iniciais em seu livro Just so Far, de 1954:

Eu nasci em Maida Vale, Londres, em 1909. Eu posso, então, declarar-me um cockney... Não posso dizer que era nada além de feliz na escola. Eu era péssimo tanto em futebol quanto em críquete... [mas] Eu não sofria pelas minhas lamentáveis performances nos campos porque logo ganhei certo renome nos palcos das peças escolares (AMIES, 1964, p. 11-21).

Significativamente, Dior escolhe relatar suas influências precoces através das descrições dos interiores de suas várias casas. "Autorretratar-se", ele repete,

é sempre dificil... Provavelmente a maneira mais simples de dar uma ideia de minha personalidade é de levá-los comigo às diferentes casas onde eu vivi da infância em diante... Tenho certeza de que a tentativa de uma biografia indireta será mais reveladora do que um relato direto de minha vida (DIOR, 1958, p. 165).

A cuidadosa lembrança da casa de sua família, em Granville, desenrola-se belamente como fios aleatórios conectando a "Casa Dior" às residências particulares de Dior:

A casa da minha infância era de um reboco levemente rosa, misturado com cascalhos cinzas e esses dois tons permanecem minhas cores favoritas na costura. Como minha mãe possuía uma paixão por plantas verdes, uma protuberância foi colocada em frente à casa sem nenhuma tentativa de harmonia - uma estufa de $1900 \mathrm{em}$ ferro forjado. Anos depois, quando me mudei 
para Paris, meu primeiro cuidado foi procurar uma casa com os mesmos atributos... A porta da frente se abria para um hall de entrada e o começo de um grande lance de escadas. Toda essa área era decorada com uma imitação de pinheiros destacados com bordas de bambu... grandes painéis pintados à imitação das estampas japonesas adornavam toda a escada. Essas versões de Utamaro e Hokusai fizeram a minha Capela Sistina. Eu me lembro de olhá-las pasmo por horas a fim, enquanto, apoiado em um exótico banquinho trabalhado em couro, eu timidamente corria os dedos nas cortinas a farfalhar com suas miçangas... Essas longas meditações me deixaram com um gosto forte pelos japonismos que se veem nas telas. Eu ainda amo aquelas sedas bordadas com flores e pássaros fantásticos e uso-as em minhas coleções (DIOR, 1958, p. 165).

Balmain, que trabalhou com Dior no ateliê Lelong, era igualmente indulgente em suas descrições dos antigos apartamentos que possuiu, decorou e apreciou. Interessantemente, ele fornece um relato elogioso sobre a casa de Dior na rue Royale:

[Era] mobiliada no estilo Segundo Império. Havia um grande piano de cauda preto no salão e o que eu recordo ser um número fantástico de bugigangas aparentemente sem valor: fotografias de senhoras idosas em porta-retratos de veludo de pelúcia, pequenas cabras douradas puxando conchas de madrepérolas montadas em rodas, pratos de fruta opalinos e, dominando tudo, um retrato imenso em tamanho real de uma mulher vestida no estilo de 1880. Ela possuía uma semelhança tão chocante com Christian que nunca imaginei que fosse apenas uma amiga da familia (BALMAIN, 1964, p. 70).

Ele continua com uma anedota igualmente reveladora sobre uma visita feita no verão por Dior à casa de campo dos Balmain durante o período da Ocupação:

Ele trouxe consigo um fox-terrier mestiço, Bobby, que nunca o deixava sozinho. Em uma caminhada para Hautecomte Abbey, mamãe pergunta brincando qual a raça de Bobby, "Ele pertence ao período de transição" Christian respondeu, "Louis XVI na frente e Louis XV atrás". Eu aprendi muito com Christian - ele era mais velho que eu, havia morado em Paris por mais tempo, e frequentava os círculos mais elegantes (BALMAIN, 1964, p. 70).

Essa evidência nas autobiografias de um apego profundo dos costureiros com o conceito de interior privado ( $\mathrm{e}$, por extensão, da vida privada como refúgio) como um espaço para ilustrar os gostos pessoais, relacio- 
namentos, alianças e as inspirações para o impulso criativo, acompanha uma preocupação em colocar detalhes ecléticos de interiores do passado, relembrados como desvios inteligentes de subversão. Essa tendência é capturada maravilhosamente por Hartnell, cuja descrição do apartamento da atriz Gertude Lawrence, em Portland Place, durante os anos 1930, é uma peça clássica das anedotas do meio "gay":

Limpando seus dedos úmidos em um longo guardanapo verde jade de babados, ela compôs um coquetel poderosissimo. Eu comecei a suar um pouco enquanto sentávamos para almoçar. A decoração da sala de jantar também me deixou de alguma maneira desabilitado. Era, eu acho, de um cinza pálido, alegrado com vasos cheios de tulipas tingidas de verde, mas as grandes janelas eram surpreendentemente cortinadas com um conjunto luxuoso de lantejoulas com glitter. Agora, como alguns devem saber, eu sou mais do que parcial sobre a alegria de lantejoulas com glitter, mas metros e metros desses objetos lindinhos aglomerados como uma casaca de malha e coruscando no sol do meio dia... não era um acompanhamento tranquilo para se comer arenque defumado com molho de mostarda (HARTNELL, 1955, p. 56).

0 historiador da arte Christopher Reed redescobriu o termo "amusing style" para descrever essa forma de design interior praticada do início ao meio do século $X X$, a qual transgredia barreiras históricas, nacionais e sexuais; sua potência como uma tela para a representação de personalidades do mundo da costura que, de outra forma, seriam reprimidas ou contidas é ainda mais vividamente ilustrada pelo relato de Hartnell de sua própria casa como ponto inicial e contexto para a produção de seus desenhos:

Em minha sala de desenhos pintada de um tom pálido, prendo metros de tecido dourado às cortinas, observando a dobra e a graça das coisas a cair, e jogo cetim colorido por duas almofadas no sofá, imaginando que sejam o busto e quadris respectivamente. Esse efeito nem sempre é feliz... A inspiração é inconsciente, ou talvez subconsciente. Os vestidos nas pinturas de grandes artistas estão normalmente em minha cabeça; os mestres italianos do traço mais puro, e toda a alegria francesa de Boucher, Watteau e Mme. Vigee le Brun; Fragonard para o folies de grandeur... com Renoir e Tissot para um toque de exagero. Os desenhos de Drian, Bakst, Sutherland, Cecil Beaton e Ronald Searle podem ajudar. Até objetos comuns como uma cesta de sardinhas ou as linhas de ferro brilhantes de uma estação de trens podem estimular as ideias para um vestido prateado de noite (HARTNELL, 1955, p. 82). 
Existe algo nessas tentativas conscientes de traçar inspirações e motivações ocultas no design dos vestidos que trazem para mais perto o entendimento do tipo de homem que encontrou tanto consolo quanto sucesso mundial em uma profissão que fora considerada, no melhor dos casos, como efeminada e, nos piores, perversa. 0 exemplo da patologização feita por Woolman Chase à aparentemente desproporcional presença de homens homossexuais no campo da moda, citada anteriormente, não foi uma ocorrência isolada. A caracterização da identidade sexual da indústria da moda feita pelo editor da Vogue Henry Yoxall foi duplamente violenta:

0 mundo da alta-costura passou por diversas revoluções durante minha jornada profissional e terminou, alguns pensam, de ponta cabeça. Em um primeiro momento, era dominado por mulheres, depois por homens e então por epicenos... Eu sempre adotei a política de permanecer como eminência parda durante as negociações da Vogue com os costureiros. Suas demandas eram tão desconcertantes... Em comparação, as prima-donas eram modestas e sensatas (YOXALL, 1966, p. 57-58).

Como se colocasse lenha na fogueira de Yoxall, Hardy Amies, em um argumento tipicamente indiferente e descaradamente misógino oferece uma interpretação dos trabalhos da indústria da costura nos meados do século XX que enfatizava sua natureza como um tipo de força homossexual para o policiamento do bom gosto:

Eu não acho que as mulheres tenham a metade da chance de obter sucesso como designers que os homens têm. Para ser um designer de sucesso você deve ser objetivo: você deve ser capaz de ver as mulheres e suas roupas como um todo: você deve ser capaz de projetar para todos os tipos de mulher e vê-las desapaixonadamente. Poucas mulheres podem fazer isso. Quando uma designer chega a uma posição acima da multidão, geralmente descobre-se que ela projeta roupas adequadas apenas para o seu tipo. Eu não acho que nenhuma mulher deva ser encorajada a pensar em si mesma como uma potencial designer de vestidos: ela deveria se tornar uma costureira de vestidos... Muitos jovens sensatos percebem que uma boa costureira se torna uma boa esposa. Meu pai percebeu. [Mas] é difícil aconselhar um jovem a como se tornar um designer de vestidos. Não se pode ensiná-lo a fazer um vestido porque nenhum homem é empregado em salas de costura de roupas femininas. Os três requisitos mais importantes são inventividade, inteligência e bom gosto. Esses não se podem ensinar. Inventividade é o estalo que chega em seu cérebro quando você, de repente, imagina um novo bolso, prega ou manga... Inteligência o deixa sensivel à atmosfera do mundo - para sentir o Zeitgeist e assim produzir 
roupas apropriadas... Gosto não pode ser ensinado, mas pode ser adquirido. Você deve nascer com o bom gosto de desejar adquirir bom gosto (AMIES, 1964, p. 175-176).

Nunca um epigrama conclusivo foi de tom mais Wildeano, se tivermos em mente o comentário de Christopher Reed na emergência, em 1920, de uma sensibilidade particular comumente chamada por seus aderentes de "camp":

Uma forma atualizada do Esteticismo, a repetição dos gostos e estilos Wildeanos, normalmente exagerada e conhecida como camp, usa os atos de citação para declarar uma distância irônica que permite um significado conotativo em vez de - até mesmo diametralmente oposto a - um conteúdo denotativo. Dessa forma, camp está normalmente relacionado à situação da homossexualidade na primeira metade (no mínimo) do século $X X$, que confiava nas formas de significação cuidadosamente calibradas para ser reconhecivel para alguns, mas não para todos. Não apenas um atributo do vestir e do comportamento: camp também estava associado com os elementos de décor visual (REED, 2004, p. 241).

Em 1964, Susan Sontag trouxe o tema à luz em seu altamente citado "Notas sobre Camp", no qual ela reuniu uma série de "anotações" resumindo as qualidades do estilo para um público mais liberal e aberto da era Pop (SONTAG, 1983, p. 106). Originalmente publicado no jornal literário The Partisan Review, e então reapresentado na coleção de ensaios de Sontag Contra a interpretação em 1966, "Notas sobre Camp" encontrou uma ressonância particular nos mundos da moda, performance, filme, arte e design durante os anos 1970. Apesar de seu conteúdo levar a refutações da própria autora e de uma geração de teóricos queer mais assertivos nos anos 1990, o conceito introduzido, com sua grande ênfase em significação e gosto, ofereceu uma ferramenta útil para desvendar aqueles significados ocultos cravados na persona pública de Dior e seus contemporâneos (MEYER, 2000). Como o semioticista Harold Beaver sugeriu:

0 homossexual é envolto em sinais, pela urgência em interpretar o que quer que transpareça, ou falhe em transparecer, entre ele mesmo e qualquer um que encontre casualmente. Ele é um consumidor prodigioso de sinais, significados ocultos, sistemas ocultos, potencialidades ocultas. A exclusão do código comum incita essa frenética busca: no vislumbre momentâneo, na figura revolvida, no gesto esporádico, no encontro fortuito, na imagem reversa, no repentino deslize, na guarda baixada. Em um instante significados podem ser expostos; mistérios arrancados e traídos... A necessidade de traçar um mundo compativel se torna a urgência em controlá-lo com uma produção incessante de sinais (os sapatos de camurça e manejos de cigarro nos anos 
1950, o couro e apetrechos de corrente nos anos 1960...), como se nada pudesse ser determinado por seleção, exceto as assinaturas; nada deduzido por conteúdo, apenas hieróglifos (BEAVER, 1999, p. 164-167).

É interessante que a interpretação de Beaver engloba os significantes estereotipados da homossexualidade nas roupas (dos sapatos de camurça ao couro), para além de referências codificadas nas obsessões infantis com o glamour e as descrições cuidadosas de design interior que os costureiros inseriram em suas reminiscências escritas. 0 vestir e a apresentação de seus corpos também revelou alinhamentos sutis (COLE, 2000). Nos retratos posados de Dior, Balmain, Hartnell e Amies, que frequentemente apareciam nas páginas da Vogue e outras revistas de sociedade durante os anos 1950 (geralmente acompanhados por musas e modelos), é notável que todos os homens adotassem ternos de estilo inglês elegantemente costurados, cujas características foram descritas por jornalistas da época como o look Eduardiano (BREWARD, 2004, p.125-150). Isso não era uma coincidência, como notou recentemente o historiador de cultura Frank Mort:

0 retorno do Eduardianismo para os homens seguiu os passos do New Look na moda feminina... 0 Eduardianismo complementava o New Look com o destaque deste último em uma elegância extravagante e o retorno a um perfil ultra feminino, promovido por meio do corte, da cor e de uma silhueta da belle époque com cinturas de vespa e longas saias ondulantes. 0 impacto social desses estilos também se emparelhava; apesar de ambos nascerem como alta moda... sua retomada promoveu um debate ansioso sobre consumismo, juventude e sexualidade (MORT, 2010, p. 81).

O look Eduardiano, com seu corte justo, detalhes recherché (colarinhos de veludo, mangas dobradas e bolsos ticket em suas formas mais extremas) e acessórios utilizados em paradas militares (chapéus coco, sapatos winkle-pickers ${ }^{3}$ extremamente polidos e guarda-chuvas firmemente enrolados ou bengalas) era uma construção complexa, referenciando tanto a resistência aristocrática frente à alfaiataria volumosa associada à cultura de massa norte-americana, a nostalgia da cordialidade homossocial do fin de siècle, quanto as atrações paradoxais do dandismo. Talvez não importe muito que entre seus primeiros adeptos estivessem aqueles homens das profissões criativas e teatrais, que procuravam formas particulares de destaque utilizando a moda como um distintivo discreto de "entendidon. Michael Bronski, em sua exploração pioneira na formação das sensibilidades gays, fornece uma racionalização convincente:

Por ter de permanecer escondida, a sensibilidade gay se expressou através da sugestão em vez da declaração, indicando com 
a aparência o que não era permitido declarar com o conteúdo. 0 engano, que fazia parte da filosofia do dândi, encaixava-se perfeitamente nas necessidades do homem gay. Não somente era possivel se expressar por meio de um estilo e não de uma declaração, como o dandismo também oferecia a possibilidade distinta de ascensão social... [já que] Sontag notou que o homem gay moderno alcança sua integração na sociedade promovendo o senso estético (BRONSKI, 1984, p. 57).

No entanto, a rebuscada discrição Eduardiana não prevaleceria. No mesmo ano da publicação do ensaio inovador de Sontag (1964), a Queen Magazine (em um exemplo brilhante de pastiche camp) anunciou a morte dos antigos estilos de costura com obituários fictícios de Balenciaga e Givenchy (WILCOX, 2007, p. 206). Como sugere a biografia dupla de Yves Saint Laurent e Karl Lagerfeld escrita por Alice Drake, uma nova geração de designers era menos reticente em trazer à tona seu status de "outsiders" na promoção de seu trabalho e reconhecimento de seu conteúdo "queer", e também em sua disposição em ter suas vidas pessoais e interiores abertas ao escrutínio público (DRAKE, 2006). Ecos da grande tradição de Dior e Balmain continuaram a reverberar, por exemplo, no autorretrato atormentado de Saint Laurent como, simultaneamente, garoto-propaganda nu para geração do jeans e mestre recluso dos palácios de contos de fada em Paris, Normandia, Marrakesh e Tânger. Em sua introdução à notória retrospectiva de Diana Vreeland sobre seu trabalho no Costume Institute of the Metropolitan Museum New York, em 1983, ele parecia canalizar a introspecção elegante de Dior:

Como F. Scott Fitzgerald, eu amo um frenesi de morte... Eu amo Visconti. A decadência me atrai. Ela sugere um novo mundo e, para mim, a luta da sociedade entre a vida e a morte é absolutamente linda... Na minha própria vida eu tenho visto o resplendor da suntuosa Paris pré-guerra.... e o esplendor de uma vigorosa alta-costura. E então eu descobri a juventude dos anos sessenta: Talitha e Paul Getty deitados em um terraço à luz das estrelas em Marrakesh, lindos e condenados... E meu coração sempre se dividiu entre as vestais da constância e os avatares da mudança (MURPHY; TERESTCHENKO, 2009, p. 14).

Mas, de certa maneira, enquanto a proposta estética de Saint Laurent defendia um "espírito de total de libertação e liberdade" através de seu abraço passional e público da sensualidade e da experimentação, o extraordinariamente controlado entusiasmo e deslumbramento que caracterizou a costura nos anos 1950 - sua requintada e afetada artificialidade - foi abandonada e destruída no processo. 0 custo a se pagar pela emancipação sexual tornada possivel por Stonewall, pelos eventos revolucionários de 1968 e pela descriminalização parcial da homossexualidade na Grã-Breta- 
nha foi, talvez, uma desvalorização do poder criativo de um sigilo imposto (WILCOX, 2007, p. 206). Hoje, é mais provável que designers de moda de alto escalão referenciem abertamente a inspiração de ícones gays em seus trabalhos e reconheçam a importância de parceiros do mesmo sexo em suas vidas sem pensar duas vezes, em vez de canalizar aspectos ocultos de suas personalidades através de elaboradas ilusões veladas.

Conforme espero que este ensaio tenha começado a demonstrar, a importância das autobiografias dos costureiros na era anterior à aceitação popular da homossexualidade na Europa e na América do Norte e à mudança para uma abertura sexual permite-nos algum investimento nas não-ditas subcorrentes sociais e culturais dessa profissão na sua Era de Ouro. Sobre as reais preferências sexuais de seus protagonistas, permaneço desinformado e respeitosamente silencioso - talvez elas não tenham nenhuma consequência no poderoso legado deixado por seus trabalhos extraordinários. Mas, de algum modo, a questão delicada do queer na costura e sua manifestação material não demanda uma resposta. Para "aqueles que sabem" o retrato falado de Christian Dior, da jornalista britânica Alison Adburgham publicado no The Guardian em 1956, diz tudo:

Sorridente, careca, de altura mediana e meia idade. Christian Dior é um homem com formato de pera. Ele se afunila até 0 par mais elegante de sapatos a cruzar a Avenida Montaigne. Eles não devem ser maiores do que 35 e são pontudos de maneira chique: bem franceses.... Sua mulher é linda e suave, não muito alta, muito feminina. Ele mesmo gosta de mulheres com bochechas rechonchudas (ele belisca as próprias bochechas, já bastante gordas); não magras e longas (ele empurra suas bochechas com os dedos e o polegar e as traz para perto da boca). Ele gosta delas sóbrias. E gosta delas sorridentes, acima de tudo sorridentes... "O mundo é um lugar dificil; as mulheres devem ser o sorriso do mundo". Nunca a banalidade saiu de modo mais charmoso dos lábios de um grande ditador. E nós a aceitamos; do mesmo modo que aceitamos tanto de Christian Dior - novos looks e novas linhas; novos chapéus, novos sapatos, novos perfumes, novas meias-calças, novas joias, novos produtos e novos absurdos (ADBURGHAM, 1966, p. 182-183). 


\section{NOTAS}

${ }^{1}$ Artigo traduzido por Matheus Hotz - hotzmths@gmail.com.

${ }^{2}$ Esta é uma versão em português do artigo "Couture as queer auto/biography", originalmente publicado em: STELLE, Valerie. A queer history of Fashion: From the Closet to the Catwalk. New Haven, London, New York: Yale University Press, Fashion Institute of Technology, 2013.

${ }^{3}$ Winkle-pickers é um estilo de sapatos usados a partir de 1950, caracterizados principalmente por bicos extremamente finos e longos.

\section{REFERÊNCIAS}

ADBURGHAM, Alison. View of Fashion. Nova Gales do Sul: George Allen \& Unwin, 1966.

AMIES, Hardy. Just So Far. Londres: Collins, 1964.

BALMAIN, Pierre. My Years and Seasons. Londres: Cassell, 1964.

BEAVER, Harold. Homosexual Signs (In memory of Roland Barthes) [1981]. In: CLETO, E. (Ed.). Camp: Queer Aesthetics and the Performing Subject. Edimburgo: Edinburgh University Press, 1999, p. 164-167.

BREWARD, Christopher. Fashioning London: Clothing and the Modern Metropolis. Oxford e Nova York: Berg, 2004.

BRONSKI, Michael. Culture Clash: The Making of Gay Sensibility. Nova York: South End Press, 1984. CHASE, Edna Woolman. Always in Vogue. Londres: Gollancz, 1954.

COLE, Shaun. Don We Now Our gay Apparel: Gays Men's Dress in the Twentieth Century. Oxford e Nova York: Berg, 2000.

DRAKE, Alicia. The Beautiful Fall: Fashion, Genius and Glorious Excess in 1970's Paris. Londres: Bloomsbury, 2006.

DIOR, Christian. Dior By Dior. The Autobiography of Christian Dior. Londres: Weidenfeld \& Nicolson, 1958.

HALPERIN, David. How to be Gay. Cambridge, Mass., London: Belknap Press of Harvard University Press, 2012.

HARTNELL, Norman. Silver and Gold. Londres: Silver and Gold, 1955.

HORNSEY, Richard. The Spiv and the Architect, Unruly Life in Postwar London. Minneapolis: University of Minnesota Press, 2010.

MEYER, Moe (Ed.). The Politics and Poetics of Camp. Londres: Routledge, 2000.

MORT, Frank. Capital Affairs: London and the Making of the Permissive Society. New Haven e Londres: Yale University Press, 2010.

MURPHY, Robert; TERESTCHENKO, Ivan. The Private World of Yves Saint Laurent \& Pierre Berge. Londres: Vendome Press, 2009.

PARKE, Catherine N. Biography: Writing Lives. Farmington Hills, Mich.: Twayne, 1996.

REED, Christopher. Bloomsbury Rooms. New Haven e Londres: Yale University Press for The Bard Graduate Center, 2004.

SONTAG, Susan. Notes on Camp [1964]. In: HARDWICK, E. (Ed.). A Susan Sontag Reader. Londres: Penguin, 1983.

WILCOX, Claire. The Golden Age of Couture. Londres: VEA, 2007.

YOXALL, Harold. A Fashion of Life. Londres: Taplinger, 1966. 